\title{
CHUVA DE SEMENTES EM ESTÁDIOS SUCESSIONAIS DE FLORESTA ESTACIONAL SEMIDECIDUAL EM VIÇOSA-MG ${ }^{1}$
}

Antonio Jorge Tourinho Braga², Eduardo Euclydes de Lima e Borges ${ }^{3}$ e Sebastião Venâncio Martins ${ }^{3}$

RESUMO - Os objetivos deste estudo foram caracterizar e avaliar a dinâmica da chuva de sementes em dois estádios sucessionais de uma Floresta Estacional Semidecidual, no campus de Viçosa, MG (2046' S e 42 $52^{\prime}$ W), da Universidade Federal de Viçosa. No estudo realizado entre o período de abril de 2007 e março de 2008 , foram reconhecidos 84 taxa, sendo 41 espécies pertencentes a 25 famílias na floresta inicial e 24 espécies pertencentes a 13 famílias na floresta avançada, cuja forma de vida dominante foi arbórea e a síndrome de dispersão predominante, a zoocórica. A densidade média de sementes na floresta inicial foi de 637,5 sementes/ $\mathrm{m}^{2}$ e na avançada, de 124,6 sementes $/ \mathrm{m}^{2}$. O índice de Sørensen de 55\% indicou baixa similaridade florística entre as sementes das espécies encontradas na chuva de sementes dos dois trechos de florestas analisados.

Palavras-chave: Ecologia de sementes; Síndromes de dispersão; Sucessão florestal.

\section{SEED RAIN IN SUCCESSIONAL STAGES OF SEMIDECIDUOUS SEASONAL FOREST IN VIÇOSA, MG}

\begin{abstract}
This study aims to describe and to evaluate seed rain dynamic in two successional stages in a seasonal semideciduous forest at the Universidade Federal de Viçosa, Viçosa campus, $M G$ (2046'S and 4252' W), Brazil. The study was conducted between April/2007 and March/2008. Eighty four taxa species were identified, 41 belonging to 25 families at the initial forest and 24 belonging to 13 families at the advanced forest. The dominant life form was arboreous and the dispersion syndrome was zoochory. The mean seed density at the initial forest was 637.5 seeds $/ \mathrm{m}^{2}$, while at the advanced forest it was $124.6 \mathrm{seeds} / \mathrm{m}^{2}$. The Sorensen index of 55\% indicated low floristic similarity between the seeds of the species found in the seed rain at the two forest portions evaluated.
\end{abstract}

Keywords: Seed ecology; Dispersal syndromes; Forest succession.

\section{INTRODUÇÃO}

A chuva de sementes é importante recurso para o surgimento de novos indivíduos e espécies nas comunidades vegetais, sendo a disponibilidade de propágulos e de agentes dispersores fundamentais para o estabelecimento estrutural da vegetação, principalmente após distúrbios (GROMBONEGUARANTTINI; RODRIGUES, 2002). As sementes presentes na chuva são provenientes da própria área e de comunidades externas, sendo o aporte destas o que determina, em parte, sua população potencial no ecossistema florestal (HARPER, 1977).
A morfologia das sementes, bem como o tipo de agente dispersor, influencia no processo, na distância alcançada pelos diásporos e na eficiência da dispersão, visto que, quanto mais distante da fonte dispersora, maior a probabilidade de estabelecimento e a contribuição para a dinâmica sucessional (VAN DER PIJL, 1982; AUGSPURGER; KELLY, 1984). Visto que sementes resultantes da dispersão de áreas afastadas podem contribuir para a riqueza de espécies e a variabilidade genética das populações presentes no local, enquanto a dispersão restrita e a escassez de indivíduos produtores restringem a diversidade da comunidade florestal (CAMPOS et al., 2009). Desse modo, a regeneração

\footnotetext{
${ }^{1}$ Recebido em 21.09.2012 aceito para publicação em 24.03.2015

${ }^{2}$ Instituto Federal Baiano, Campus Catu, Catu, BA - Brasil. E-mail: <antonio.braga@catu.ifbaiano.edu.br>.

${ }^{3}$ Universidade Federal de Viçosa, Departamento de Engenharia Florestal, Viçosa, MG - Brasil. E-mail: <venancio@ufv.br> e<elborges@ufv.br>.
} 
nas florestas tropicais depende da potencialidade de reposição de indivíduos e da recomposição de espécies que, por sua vez, estão na dependência da disponibilidade de sementes (PENHALBER; MANTOVANI, 1997). Portanto, a análise das variações de disponibilidade de sementes de espécies arbóreas, pelo registro dos padrões de chuvas de sementes, ao longo de determinado período contribui para esclarecer questões sobre a diversidade de componentes em comunidades vegetais e os processos envolvidos nos estádios de sucessão. Além disso, o conhecimento da variação da chuva de sementes ao longo do tempo é fundamental para a compreensão dos processos reprodutivos e da dinâmica da vegetação (HOFGAARD, 1993), também fornece informações importantes sobre a abundância, distribuição espacial eriqueza de espécies (GROMBONE-GUARATINI; RODRIGUES, 2002).

Ante o exposto, neste estudo o objetivo foi caracterizar e avaliar a dinâmica da chuva de sementes no concernente à composição florística, à densidade, à frequência, às síndromes de dispersão envolvidas e à sazonalidade no período de um ano em dois trechos de um fragmento de Floresta Estacional Semidecidual em estádios distintos, localizados em Viçosa, MG.

\section{MATERIAL E MÉTODOS}

O estudo foi conduzido em um fragmento florestal denominado Mata da Agronomia, que possui aproximadamente 50 ha, localizado no Campus da Universidade Federal de Viçosa, na cidade de Viçosa, Zona da Mata do Estado de Minas Gerais (2046’ S e42 ${ }^{\circ} 2^{\prime}$ W), com altitude variando entre 688 e $782 \mathrm{~m}$.

A topografia do local apresenta gradiente pedogeomorfológico, com topos planos ocupados com Latossolos Distróficos e ricos em alumínio, que dão passagem a rampas coluviais com Latossolos mais rasos e câmbicos e fundos de grotas, em posições abaciadas com predomínio de Cambissolos Epieutróficos ricos em nutrientes (FERREIRA JÚNIOR et al., 2012). O clima da região, através do sistema de Köppen, é do tipo Cwb, mesotérmico com verões chuvosos, invernos frios e secos; a temperatura média anual é de $19^{\circ} \mathrm{C}$; e a umidade relativa do ar varia em torno de $80 \%$, sendo a precipitação média anual de $1.314 \mathrm{~mm}$ (CASTRO et al., 1983).

A vegetação da Mata da Agronomia é caracterizada como Floresta Estacional Semidecidual montana (VELOSO et al., 1991), compondo um mosaico de diferentes estádios sucessionais. Essa mata possui histórico de mais de 50 anos de regeneração natural, instaurada após a cobertura vegetal original ter sido substituída, por meio do corte raso, pelo plantio sequencial de café e pastagem.

Um dos trechos escolhidos, denominado neste estudo floresta inicial, encontra-se em processo de regeneração substituindo a pastagem há aproximadamente 28 anos. Esse trecho situa-se bem às margens do aceiro que faz divisa com o campo experimental Prof. Diogo Alves Melo (2046.105'S e 42 $\left.52.061^{\prime} \mathrm{W}\right)$, com altitude variando entre 688 e $737 \mathrm{~m}$. O outro trecho de floresta com mais de 50 anos foi denominado floresta avançada e encontra-se em estádio avançado de sucessão, adentrando a mata $\left(20^{\circ} 46.197^{\prime} \mathrm{S}\right.$ e $\left.42^{\circ} 52.061^{\prime} \mathrm{W}\right)$, com atitude entre 708 e $782 \mathrm{~m}$. Em cada um dos trechos, foram realizados previamente estudos fitossociológicos em 10 parcelas de 25 x 10 m, utilizando critério de inclusão de CAP e" 15 cm (BRAGA et al., 2011).

Para avaliar a chuva de sementes nas florestas inicial e avançada, foram utilizados 10 coletores de $1 \mathrm{~m}^{2}(1 \times 1 \mathrm{~m})$ com fundo de tela de náilon de $1 \mathrm{~mm}$ de malha, em cada trecho estudado, totalizando 20 coletores. Estes foram distribuídos, de forma sistemática, no centro de cada parcela $(25 \times 10 \mathrm{~m})$, a uma altura de $70 \mathrm{~cm}$ da superfície do solo, distantes $15 \mathrm{~m}$ entre si.

O material interceptado por cada coletor foi recolhido mensalmente durante o período de 12 meses, de abril de 2007 a março de 2008, levado para o Laboratório de Sementes Florestais do Departamento de Engenharia Florestal da Universidade Federal de Viçosa, onde, após a secagem prévia à sombra, foi realizada a triagem das sementes. Os diásporos foram identificados e quantificados, e as famílias foram reconhecidas de acordo com o sistema APG II (Angiosperm Phylogeny Group II, 2003). A confirmação dos nomes das espécies e de seus autores foi obtida através de consultas ao site Missouri Botanical Garden (http://www.mobot.org), bem como através da literatura especializada.

A densidade (DA) e frequência absolutas (FA) da chuva de sementes foram calculadas para as sementes de cada espécie, inclusive as indeterminadas, sendo $\mathrm{DA}=\mathrm{n} / \mathrm{A}$ e $\mathrm{FA}=100 \mathrm{x}(\mathrm{p} / \mathrm{P})$, em que $\mathrm{n}=$ número de sementes de cada espécie, $\mathrm{A}=$ área amostrada $\left(\mathrm{m}^{2}\right)$, $\mathrm{p}=$ número de amostras com cada espécie e $\mathrm{P}=$ número total de amostras. A similaridade florística entre as sementes das espécies identificadas na chuva de

Revista Árvore, Viçosa-MG, v.39, n.3, p.475-485, 2015

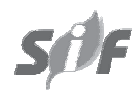


sementes e as espécies arbóreas amostradas nas parcelas de cada trecho, foi calculada pelo índice de similaridade de Sørensen (MUELLER-DOMBOIS; ELENBERG, 1974; BRAGA et al., 2011). Os taxa foram classificados quanto à forma de vida (arbórea e liana) e separados quanto à síndrome de dispersão (VAN DER PIJL, 1982).

As sementes das espécies arbóreas amostradas foram classificadas em categorias sucessionais, conforme os critérios adotados por Gandolfi et al. (1995), além de classificações adotadas nos estudos de Martins e Rodrigues (2002) e Martins et al. (2002). Os taxa com informações divergentes ou ausentes foram catalogados como "não classificado". Também, foram realizadas comparações entre a quantidade mensal e total de sementes precipitadas nas florestas inicial e avançada, por meio do teste de Student para amostras não pareadas.

\section{RESULTADOS}

Durante o período de estudo foram coletadas 7.621 sementes, das quais 6.276 eram de espécies arbóreas, 908 de lianas e 437 sementes de espécies não classificadas, sendo o número de sementes provindas da floresta inicial (5.541) significativamente superior $(\mathrm{p}=0,0004)$ às da floresta avançada (734).

No total foram identificados 84 taxa entre as sementes coletadas nos dois trechos de florestas, correspondentes a 46 espécies, distribuídas em 30 gêneros pertencentes a 23 famílias. Oito sementes foram identificadas apenas no nível de gênero, nove em nível de família e 38 não classificadas (Tabela 1). Trinta e duas sementes de espécies comuns aos dois trechos, enquanto 38 foram encontradas apenas na floresta inicial e 14, unicamente na floresta avançada.

A identificação por espécies das sementes coletadas na floresta inicial indicou 41 espécies pertencentes a 25 famílias, sendo $81 \%$ das sementes coletadas provindas de indivíduos de hábito arbóreo. Enquanto na floresta avançada foram coletadas e identificadas sementes de 24 espécies pertencentes a 13 famílias, sendo a maior porcentagem de sementes também oriundas de indivíduos arbóreos (76\%).

Considerando os dois trechos de florestas estudados, as famílias Bignoneaceae e Fabaceae destacaram-se das demais na chuva de sementes com quatro espécies cada. Com relação aos trechos de floresta estudados, a família de destaque na floresta inicial foi Bignoneaceae com quatro espécies, enquanto na floresta avançada as famílias Annonaceae, Bignoneaceae e Fabaceae se destacaram com três espécies cada.

Contabilizando as sementes de ambos os trechos do estudo, as espécies pioneiras de hábito arbóreo Cecropia glaziovii $(\mathrm{n}=2.287)$, C. hololeuca $(\mathrm{n}=1.478)$, Allophylus sericeus $(\mathrm{n}=835)$ e Croton urucurana $(\mathrm{n}=411)$ concentraram $79,8 \%$ das amostras coletadas, sendo, assim, as espécies com maior contribuição para o armazenamento do banco de sementes da mata (Figura 1).

As sementes de C. glaziovii concentraram-se na floresta inicial (96\%), onde se encontra uma população de 44 indivíduos dessa espécie, enquanto as sementes de C. hololeuca, com apenas um indivíduo amostrado na primeira parcela da floresta inicial, esteve presente em todos os coletores de ambos os trechos de floresta, sendo $83 \%$ das sementes dispersas, amostradas na floresta inicial.

$\mathrm{Na}$ análise geral do fragmento florestal, a síndrome de dispersão zoocórica (54\%) predominou sobre a anemocórica ( $42 \%$ ) e autocórica (4\%), e, entre as sementes com síndrome zoocórica, $87 \%$ eram de espécies com hábito arbóreo, o mesmo comportamento de hábito observado na síndrome de dispersão anemocórica (70\%). $\mathrm{Na}$ análise setorial da floresta inicial e avançada, a dispersão zoocórica seguiu a tendência geral, com 64 e $52 \%$, respectivamente, em relação às demais síndromes de dispersão.

Quanto ao padrão de variação temporal da produção de sementes, observou-se que as maiores deposições ocorreram no final da estação chuvosa em ambos os estádios de sucessão, sendo o pico de produção na floresta inicial no mês de março e na floresta avançada no mês de abril (Figura 2). Na floresta inicial, constatouse um segundo pico de produção no final da estação seca entre os meses de setembro e outubro, enquanto na floresta avançada a deposição de sementes permaneceu regular no restante do ano.

A deposição de sementes de espécies arbóreas na floresta inicial foi superior às das lianas por quase todo o período estudado, excetuando-se o mês de maio, início da estação seca na região quando a quantidade de sementes de lianas superou a de arbóreas. Porém, o pico de deposição de sementes de lianas ocorreu no mês de setembro, no final da estação seca, enquanto a maior deposição de sementes de arbóreas ocorreu no mês de março, que corresponde ao final da estação chuvosa na região (Figura 3 ).

Revista Árvore, Viçosa-MG, v.39, n.3, p.475-485, 2015

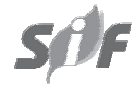


Tabela 1 - Espécies, formas de vida (FV), síndromes de dispersão (SD), categoria sucessional (CS) e períodos de coleta dos taxa encontrados na chuva de sementes em dois trechos de Floresta Estacional Semidecidual em Viçosa, MG, Brasil. Arb = arbustiva, Arv = arbórea, Lia = liana, Ane = anemocórica, Aut $=$ autocórica, Zoo $=$ zoocórica, PI = pioneira, $\mathrm{SI}=$ secundária inicial, $\mathrm{ST}=$ secundária tardia $\mathrm{e} ?=$ desconhecido. Os traços entre os meses indicam períodos de tempo contínuos

Table 1 - Species, life form (FV), dispersal syndrome (SD), succession category (CS) and collection periods of the taxa species found in the seed rain in two portions of Semideciduous Seasonal Forest in Viçosa, MG, Brazil. Where: Arb = shrub, Arv =tree, Lia = liana, Ane = anemocory, Aut = autochory, Zoo = zoochory, PI = pioneer species, SI= initial secondary specie, $S T=$ late secondary specie, ? = unnoted. The line between months indicate continuous time period

\begin{tabular}{|c|c|c|c|c|c|}
\hline \multirow{2}{*}{ Família/Espécie } & \multirow{2}{*}{ FV } & \multirow{2}{*}{ SD } & \multirow{2}{*}{ CS } & \multicolumn{2}{|c|}{ Período da coleta } \\
\hline & & & & Floresta inicial & Floresta avançada \\
\hline \multicolumn{6}{|l|}{ ANACARDIACEAE } \\
\hline $\begin{array}{l}\text { Tapirira guianensis Aubl. } \\
\text { ANNONACEAE }\end{array}$ & Arv & Zoo & SI & Fev. & - \\
\hline Rollinia silvatica Mart. & Arv & Zoo & SI & Abr. & Out. \\
\hline Rollinia sp. & Arv & Zoo & SI & Jul.; Set.; Fev. & Nov. \\
\hline \multicolumn{5}{|l|}{ APOCYNACEAE } & Abr. \\
\hline Aspidosperma sp. & Arv & Ane & $\mathrm{ST}$ & Maio; Ago. & - \\
\hline $\begin{array}{l}\text { Indet. } 1 \\
\text { ARECACEAE }\end{array}$ & Arv & Ane & - & Maio & - \\
\hline $\begin{array}{l}\text { Syagrus romanzoffiana (Cham.) Glassm. } \\
\text { ASTERACEAE }\end{array}$ & Arv & Zoo & SI & Out. & Nov. \\
\hline Vernonanthura diffusa (Less.) H.Rob. & Arv & Ane & P I & Abr.; Ago. & Ago. \\
\hline Indet. 1 & Arv & Ane & - & Set.-Out. & Set.-Out. \\
\hline \multicolumn{6}{|l|}{ BIGNONIACEAE } \\
\hline Jacaranda sp. & Arv & Ane & $\mathrm{ST}$ & Out. & - \\
\hline Sparattosperma leucanthum (Vell.) K. Schum. & Arv & Ane & $\mathrm{SI}$ & Jun.-Jul.; Set.; Fev. & Set.-Out. \\
\hline Indet. 1 & Arv & Ane & - & Ago. & Maio-Ago. \\
\hline Indet. 2 & Arv & Ane & - & Set.-Out. & Nov. \\
\hline \multicolumn{6}{|l|}{ CANNABACEAE } \\
\hline $\begin{array}{l}\text { Trema micrantha Blume } \\
\text { ERYTHROXYLACEAE }\end{array}$ & Arv & Zoo & P I & Out.; Dez.-Fev. & - \\
\hline $\begin{array}{l}\text { Erythroxylum pelleterianum A. St. Hil. } \\
\text { EUPHORBIACEAE }\end{array}$ & Arv & Zoo & $\mathrm{SI}$ & Jan.-Fev. & Dez.-Mar. \\
\hline Croton urucurana Baill. & Arv & Aut & P I & Fev.-Jul. & - \\
\hline $\begin{array}{l}\text { Mabea fistulifera Mart. } \\
\text { FABACEAE }\end{array}$ & Arv & Aut & P I & Abr.;Jul.-Out.; Dez.; Mar. & - \\
\hline Anadenanthera peregrina (L.) Speng. & Arv & Ane & SI & Set.-Out.; Dez. & Jul.;Set.-Out. \\
\hline Dalbergia nigra Allem. Ex Benth. & Arv & Ane & SI & - & Mar. \\
\hline Rhynchosia minima (L.) DC. & Lia & Auto/Zoo & - & Maio-Jun.; Dez. & - \\
\hline Indet. 01 & Lia & Ane & - & Ago.-Out.; Dez. & Ago. \\
\hline \multicolumn{6}{|l|}{ LAMIACEAE } \\
\hline $\begin{array}{l}\text { Aegiphila sellowiana Cham. } \\
\text { LAURACEAE }\end{array}$ & Arv & Zoo & P I & Out.; Dez.-Jan. & - \\
\hline Ocotea laxa Mez & Arv & Zoo & $\mathrm{SI}$ & Out. & - \\
\hline Persea sp. & Arv & Zoo & - & Set. & - \\
\hline Indet. 01 & Arv & Zoo & - & Nov. & - \\
\hline \multicolumn{6}{|l|}{ LECYTHIDACEAE } \\
\hline $\begin{array}{l}\text { Cariniana estrellensis (Raddi) Kuntze. } \\
\text { MALPIGHIACEAE }\end{array}$ & Arv & Ane & $\mathrm{ST}$ & - & Ago.-Out. \\
\hline $\begin{array}{l}\text { Indet. } 01 \\
\text { MALVACEAE }\end{array}$ & Lia & Ane & - & Ago.-Nov. & Abr.; Jun.-Out. \\
\hline $\begin{array}{l}\text { Ceiba speciosa (A. St.-Hil.) Ravenna. } \\
\text { MELIACEAE }\end{array}$ & Arv & Ane & SI & Set. & - \\
\hline Guarea kunthiana A. Juss. & Arv & Zoo & $\mathrm{ST}$ & Mar. & - \\
\hline Trichilia catigua A. Juss. & Arv & Zoo & $\mathrm{ST}$ & Dez.-Jan. & - \\
\hline Trichilia palida Mart. & Arv & Zoo & ST & Fev. & - \\
\hline Maclura tinctoria (L.) D. Don ex Steud. & Arv & Zoo & SI & Maio; Dez. & - \\
\hline
\end{tabular}

Revista Árvore, Viçosa-MG, v.39, n.3, p.475-485, 2015 
Tabela 1 - Cont.

Table 1 - Cont.

\begin{tabular}{|c|c|c|c|c|c|}
\hline \multirow[t]{2}{*}{ Família/Espécie } & \multirow[t]{2}{*}{$\mathrm{FV}$} & \multirow[t]{2}{*}{ SD } & \multirow[t]{2}{*}{ CS } & \multicolumn{2}{|c|}{ Período da coleta } \\
\hline & & & & Floresta inicia & Floresta avançada \\
\hline \multicolumn{6}{|l|}{ MYRTACEAE } \\
\hline $\begin{array}{l}\text { Eucalyptus sp. } \\
\text { RUBIACEAE }\end{array}$ & Arv & Ane & - & Abr.; Nov.-Jan & n. \\
\hline Coffea arabica L. & Arv & Zoo & - & Abr.; Dez. & Abr. \\
\hline $\begin{array}{l}\text { Coutarea hexandra (Jacq.) K. Schum. } \\
\text { SALICACEAE }\end{array}$ & Arv & Ane & SI & - & Mar.-Ago.; Out. \\
\hline Casearia arborea (Rich.) Urb. & Arv & Zoo & SI & Abr. & Nov \\
\hline Casearia sylvestris SW. & Arv & Zoo & SI & Jul.; Fev.-Mar & Jul. \\
\hline Casearia sp. 1 & Arv & Zoo & SI & - & Jan.; Mar. \\
\hline \multicolumn{6}{|l|}{ SAPINDACEAE } \\
\hline Allophylus edulis Radlk. Ex Warm. & Arv & Zoo & SI & - & Jan \\
\hline Allophylus sericeus Radlk. & Arv & Zoo & SI & Dez.-Mar. & - \\
\hline Indet. 01 & Arv & Zoo & - & Jan. & - \\
\hline \multicolumn{6}{|l|}{ SOLANACEAE } \\
\hline Solanum sp. 01 & Arb & Zoo & - & Abr. & - \\
\hline Solanum sp. 02 & Arb & Zoo & - & \multicolumn{2}{|c|}{ Ago.-Out.; Dez.-Jan.Ago.; Out.-Nov.; Dez.-Mar. } \\
\hline Indet. 01 & Arb & Zoo & - & Set. & - \\
\hline \multicolumn{6}{|l|}{ URTICACEAE } \\
\hline Cecropia glaziovii Sneth & Arv & Zoo & PI & Jan.-Nov. & Abr.-Maio; Out.; Dez.; Jan. \\
\hline Cecropia hololeuca Miq. & Arv & Zoo & PI & Abr.-Mar. & Abr.-Mar. \\
\hline \multicolumn{6}{|l|}{ INDETERMINADA } \\
\hline Indet. 1 & Lia & Zoo & - & Mar.-Dez. & Abr.; Maio; Jul.; Jan. \\
\hline Indet. 2 & Lia & Ane & - & Abr & Nov.; Fev. \\
\hline Indet. 3 & Lia & Ane & - & Abr; Jun & Abr. \\
\hline Indet. 4 & Lia & Zoo & - & Abr.; Mar. & Abr.; Maio; Jun.; Mar. \\
\hline Indet. 5 & Lia & Zoo & - & Abr. & - \\
\hline Indet. 6 & Lia & Ane & - & Ago. & - \\
\hline Indet. 7 & Lia & Ane & - & - & Mar. \\
\hline Indet. 8 & $?$ & Ane & - & Abr. & - \\
\hline Indet. 9 & ? & Ane & - & Abr. & - \\
\hline Indet. 10 & $?$ & $?$ & - & Abr. & - \\
\hline Indet. 11 & ? & ? & - & Abr. & - \\
\hline Indet. 12 & $?$ & ? & - & Abr. & - \\
\hline Indet. 13 & ? & ? & - & Abr.-Set. & Abr.-Ago. \\
\hline Indet. 14 & ? & ? & - & Mar.-Set. & Abr.-Jun.; Dez.-Jan. \\
\hline Indet. 15 & ? & ? & - & Abr. & Abr. \\
\hline Indet. 16 & $?$ & ? & - & - & Abr. \\
\hline Indet. 17 & ? & $?$ & - & - & Abr. \\
\hline Indet. 18 & ? & ? & - & Maio & - \\
\hline Indet. 19 & ? & ? & - & - & Maio \\
\hline Indet. 20 & $?$ & Ane & - & Jun. & - \\
\hline Indet. 21 & ? & $?$ & - & - & Jun. \\
\hline Indet. 22 & ? & $?$ & - & Jul. & - \\
\hline Indet. 23 & ? & $?$ & - & Jul.; Set. & Jan. \\
\hline Indet. 24 & $?$ & Ane & - & - & Ago. \\
\hline Indet. 25 & ? & $?$ & - & Set. & - \\
\hline Indet. 26 & $?$ & $?$ & - & Out. & Set. \\
\hline Indet. 27 & $?$ & $?$ & - & Out. & - \\
\hline Indet. 28 & $?$ & $?$ & - & Nov.-Jan. & Dez. \\
\hline Indet. 29 & $?$ & $?$ & - & - & Nov \\
\hline Indet. 30 & $?$ & ? & - & Dez. & - \\
\hline Indet. 31 & $?$ & $?$ & - & Jan. & - \\
\hline Indet. 32 & $?$ & $?$ & - & Jan. & Jan.-Fev. \\
\hline Indet. 33 & ? & $?$ & - & Jan.-Fev. & Jan.-Fev. \\
\hline Indet. 34 & $?$ & $?$ & - & - & Jan. \\
\hline Indet. 35 & $?$ & $?$ & - & Fev. & Fev. \\
\hline Indet. 36 & ? & $?$ & - & Fev. & - \\
\hline Indet. 37 & $?$ & $?$ & - & Mar. & - \\
\hline Indet. 38 & $?$ & $?$ & - & - & Mar. \\
\hline
\end{tabular}




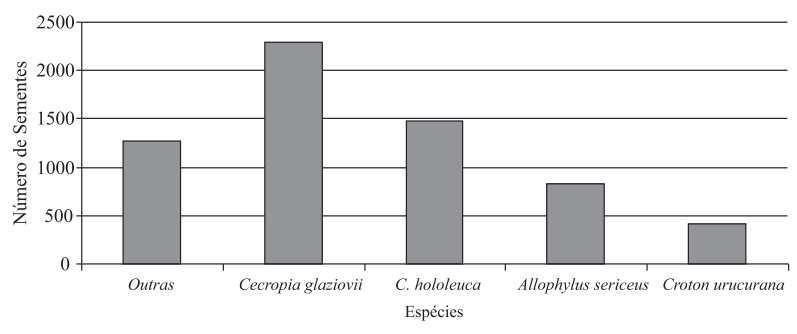

Figura 1 - Espécies de maior contribuição para a chuva de sementes na mata da Agronomia, Viçosa, MG.

Figure 1 - Species with major contribution for the seed rain in Mata da Agronomia, Viçosa-MG.

Floresta Inicial

$\rightarrow$ Arbórea $\rightarrow$ Liana

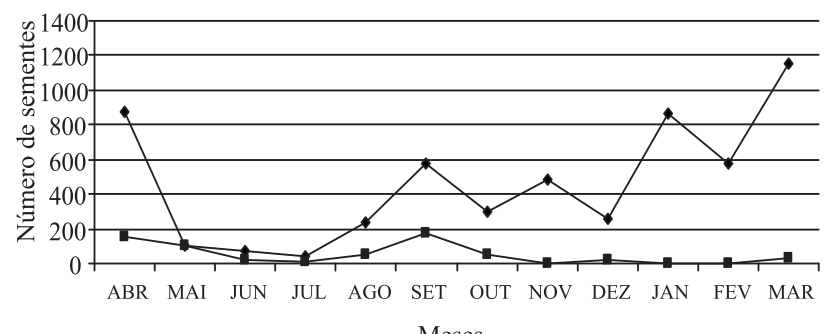

Meses

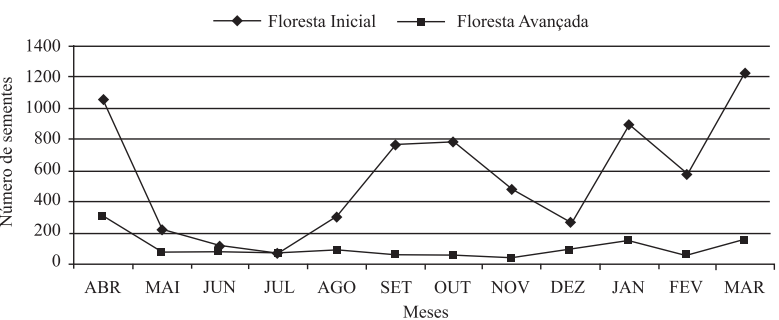

Figura 2 - Deposição mensal de sementes nas florestas inicial e avançada da mata da Agronomia, Viçosa, MG.

Figure 2 - Monthly deposition of seeds for initial and advanced forests in Mata da Agronomia, Viçosa, MG.

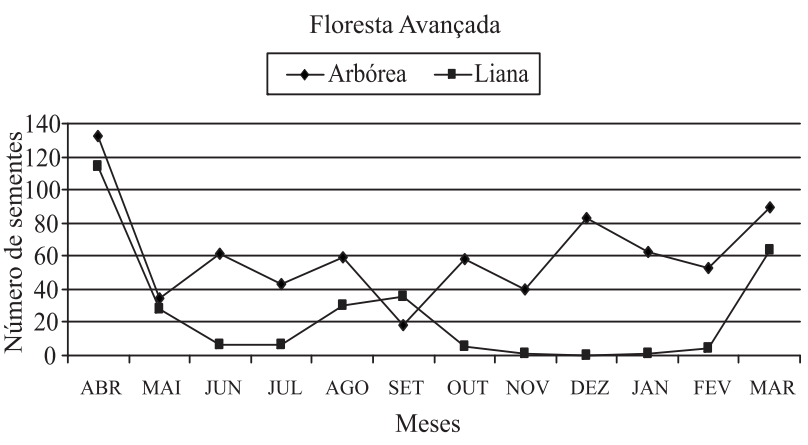

Figura 3 - Deposição mensal de sementes arbóreas e lianas nas florestas inicial e avançada da mata da Agronomia, Viçosa-MG. Figure 3 - Monthly deposition of trees and liana seeds for initial and advanced forests in Mata da Agronomia, Viçosa-MG.

$\mathrm{Na}$ floresta avançada à quantidade de sementes de arbóreas depositadas, foi superior às de lianas durante quase todo o período analisado, e a maior deposição de sementes de lianas em relação à das arbóreas aconteceu no final da estação seca (setembro). Entretanto, ao contrário do ocorrido na floresta inicial, o pico ocorreu em conjunto com o das sementes arbóreas no mês de abril, que corresponde ao final da estação chuvosa e início da estação seca.

A densidade média na floresta inicial foi de 637,5 sementes $/ \mathrm{m}^{2}$, o que corresponde a 6.375 .000 sementes/ ha, e na floresta avançada, de 124,6 sementes $/ \mathrm{m}^{2}$, ou 1.246.000 sementes/ha. Na densidade e frequência absolutas das espécies constituintes da chuva de sementes nos trechos de floresta estudados, houve variação, refletindo a sua alta resiliência (Tabela 2).

$\mathrm{Na}$ floresta inicial estiveram presentes $83,3 \%$ dos 84 taxa coletados, e 55,9\% deles tinham frequência absoluta baixa ( $\leq 10 \%$ ), conforme Grombone-Guaratini e Rodrigues (2002) e Campos et al. (2009). O mesmo ocorreu na floresta avançada representada por $54,8 \%$ dos taxa, com a maioria das espécies $(71,4 \%)$ apresentando frequência absoluta menor que $10 \%$. Os cinco taxa que contribuíram com as maiores densidades absolutas na floresta inicial foram Cecropia glaziovii, Cecropia hololeuca, Allophylus sericeus, Croton urucurana e Asteraceae sp 1, enquanto na floresta avançada a contribuição foi das espécies $C$. hololeuca e Coutarea hexandra, Malpighiaceae sp 1 , Indet. 14 e Indet. 7.

A similaridade florística obtida pelo índice de Sørensen entre as sementes das espécies da chuva de sementes e as arbóreas amostradas nas mesmas parcelas onde foram instalados os coletores foi de $48 \%$ na floresta inicial e de $29 \%$ na avançada, sendo $55 \%$ a similaridade entre as sementes das espécies precipitadas nas florestas inicial e avançada.

\section{DISCUSSÃO}

O grande número de sementes presentes na floresta inicial demonstra o ritmo de produção das espécies pioneiras que predominam em número de indivíduos e são características desse estádio sucessional. Em

Revista Árvore, Viçosa-MG, v.39, n.3, p.475-485, 2015 
contrapartida, o menor número de sementes procedentes da floresta avançada pode estar relacionado ao ciclo de produção descontínuo dos indivíduos das espécies mais tardias presentes nesse trecho. Segundo Leitão Filho et al. (1993), as espécies pioneiras têm rápido crescimento, com grande produção de flores e frutos em curto espaço de tempo devido ao ciclo de vida curto.

O estudo da chuva de sementes conduzido nesse fragmento de Floresta Estacional Semidecidual indicou as famílias Fabaceae e Bignoneaceae como as de maior destaque em número de espécies, e o mesmo ocorreu no estudo da chuva de sementes realizado em um fragmento denominado "mata da biologia", localizado próximo à área desta pesquisa, sendo todas as sementes dessas duas famílias amostradas da forma de vida arbórea e liana, respectivamente (CAMPOS et al., 2009).

A exemplo do observado neste estudo, o predomínio de espécies arbóreas em relação às de lianas foi verificado também na pesquisa de Campos et al. (2009), que avaliaram a chuva de sementes em outro fragmento de Floresta Estacional Semidecidual localizada também no Município de Viçosa, assim como nos estudos de chuva de sementes de Araújo et al. (2004) em uma Floresta Estacional Decidual em Cachoeira do Sul, RS, e de Penhalber e Mantovani (1997), em uma floresta secundária em São Paulo, SP.

Para a espécie C. hololeuca, mesmo com a baixa densidade de indivíduos dentro da área de estudo foram amostradas sementes em todas as parcelas de ambos os trechos estudados, uma vez que o grande alcance de dispersão de suas sementes da espécie se deve a um de seus agentes dispersores, Penelope sp. (jacu), ave comum na região, que come os frutos e dispersa suas sementes por meio das fezes. Segundo Martini e Santos (2007), maior densidade de árvores e riqueza de espécies atrai e favorece a permanência de animais dispersores responsáveis pelo transporte de propágulos do entorno, enriquecendo a chuva de sementes; em contrapartida, locais abertos podem reduzir a riqueza de espécies observadas na chuva de sementes.

Nesse tipo de pesquisa, torna-se importante evidenciar que o grande número de sementes não identificadas é habitual, pois, unindo a dificuldade para determinação de um táxon, alia-se a condição morfológica em que as sementes são encontradas, muitas delas danificadas ou deterioradas, por vezes procedentes das fezes de seus dispersores, a exemplo do jacu e de outros pássaros.
O predomínio da síndrome de dispersão zoocórica neste estudo não acompanhou o obtido por Campos et al. (2009) na "mata da biologia", onde a síndrome de dispersão anemocórica predominou nos dois anos de avaliação da chuva de sementes. Entretanto, no estudo de Yamamoto et al. (2007), que pesquisaram a síndrome de dispersão em um fragmento de Floresta Estacional Semidecidual montana no Município de Pedreira, SP, foi verificado que a maioria das espécies tinha síndrome zoocórica e ainda, durante quase todo o ano, a zoocoria predominou sobre as demais síndromes. Fator que pode estar relacionado à localização, ao grau de proteção ou do acesso à área, pois a presença constante de pessoas no local e outras ações antrópicas in loco ou, mesmo, em seu entorno, podem afetar a ação da fauna dispersora no fragmento.

De maneira geral, a síndrome de dispersão zoocórica em um ecossistema tropical é mais frequente que a anemocórica, predominando, principalmente, em florestas de climas úmidos ou de estacionalidade pluvial amena (VAN DER PIJL, 1982; GENTRY, 1983). No entanto, a variação na quantidade de sementes no decorrer dos meses pode estar associada a fatores como espécies frutificando próxima ou sobre os coletores, frequência de produção, síndrome de dispersão e dispersores envolvidos, assim como a estratificação da vegetação, a direção dos ventos, entre outros (ARAUJO et al., 2004).

Durante o período de coleta foi observada a frutificação de espécies próximas aos coletores, com destaque para as populações de Allophylus sericeus e C. glaziovii, que são encontradas agrupadas na floresta inicial (BRAGA et al., 2011) e têm padrão zoocórico de dispersão, cujo dispersores Coendou sp. (ouriço-caixeiro) e Penelope sp. (jacu), respectivamente, foram observados em indivíduos das espécies citadas. Na floresta avançada, destaque para a população de Cariniana estrellensis que apresentou tendência ao agrupamento e tem síndrome anemocórica de dispersão de suas sementes, o que pode explicar a baixa densidade de sementes depositadas nos coletores de forma aleatória, quando comparadas com as sementes das populações destacadas no trecho anterior.

A baixa similaridade florística entre as sementes das espécies da chuva de sementes e as espécies arbóreas amostradas pode estar relacionada à floração e frutificação delas durante o período de estudo. Além disso, fatores como a topografia do terreno podem influenciar na distribuição das espécies arbóreas presentes na área (BRAGA et al., 2011) e interferir na dinâmica da chuva

Revista Árvore, Viçosa-MG, v.39, n.3, p.475-485, 2015 
Tabela 2 - Espécies, densidade (DA) e frequência (FA) absolutas da chuva de sementes, em dois trechos de Floresta Estacional Semidecidual em Viçosa, MG, Brasil. Os taxa foram ordenados de forma decrescente de densidade absoluta da floresta inicial. * = espécies com maiores densidades na floresta avançada $\mathrm{e}^{* *}=$ sementes não contabilizadas

Table 2 - Species, absolute density (DA) and frequency (FA) of the seed rain in two sites of Semideciduous Seasonal Forest in Viçosa, MG, Brazil. The taxa species were in decreasing order according to the absolute density of the initial forest. * = species with higher density in advanced forest, ** = not calculated seeds

\begin{tabular}{|c|c|c|c|c|c|c|c|}
\hline \multirow{2}{*}{ Família } & \multirow{2}{*}{ Espécie } & \multicolumn{3}{|c|}{ Floresta inicial } & \multicolumn{3}{|c|}{ Floresta avançada } \\
\hline & & $\mathrm{N}$ & $\mathrm{DA}\left(\mathrm{m}^{2}\right)$ & FA $(\%)$ & $\mathrm{N}$ & $\mathrm{DA}\left(\mathrm{m}^{2}\right)$ & FA (\%) \\
\hline \multirow{2}{*}{ URTICACEAE } & Cecropia glaziovii Sneth & 2196 & 219,6 & 100 & 51 & 5,1 & 40 \\
\hline & Cecropia hololeuca Miq. * & 1232 & 123,2 & 100 & 238 & 23,8 & 100 \\
\hline SAPINDACEAE & Allophylus sericeus Radlk. & 835 & 83,5 & 40 & 0 & 0 & 0 \\
\hline EUPHORBIACEAE & Cróton urucurana Baill. & 411 & 41,1 & 40 & 0 & 0 & 0 \\
\hline ASTERACEAE & Espécie 1 & 352 & 35,2 & 100 & 18 & 1,8 & 100 \\
\hline MALPIGHIACEAE & Indet. 01 & 187 & 18,7 & 90 & 120 & 12 & 100 \\
\hline MELIACEAE & Guarea kunthiana A. Juss. & 117 & 11,7 & 10 & 0 & 0 & 0 \\
\hline \multirow[t]{3}{*}{ INDETERMINADA } & Indet. $1 *$ & 89 & 8,9 & 80 & 31 & 3,1 & 30 \\
\hline & Indet. 3 & 72 & 7,2 & 20 & 1 & 0,1 & 10 \\
\hline & Indet. 13 & 72 & 7,2 & 70 & 23 & 2,3 & 20 \\
\hline LAMIACEAE & Aegiphila sellowiana Cham. & 55 & 5,5 & 20 & 0 & 0 & 0 \\
\hline SALICACEAE & Casearia sylvestris SW. & 53 & 5,3 & 40 & 2 & 0,2 & 10 \\
\hline FABACEAE & Indet. $01 *$ & 47 & 4,7 & 50 & 27 & 2,7 & 20 \\
\hline \multirow{2}{*}{ INDETERMINADA } & Indet. 33 & 45 & 4,5 & 40 & 18 & 1,8 & 20 \\
\hline & Indet. 37 & 40 & 4 & 10 & 0 & 0 & 0 \\
\hline ANNONACEAE & Xylopia sericea St. Hil & 35 & 3,5 & 20 & 2 & 0,2 & 10 \\
\hline MELIACEAE & Trichilia catigua A. Juss. & 34 & 3,4 & 10 & 0 & 0 & 0 \\
\hline \multirow[t]{2}{*}{ BIGNONIACEAE } & Sparattosperma leucanthum & & & & & & \\
\hline & (Vell.) K. Schum. & 32 & 3,2 & 30 & 3 & 0,3 & 20 \\
\hline \multirow[t]{2}{*}{ INDETERMINADA } & Indet. $4 *$ & 27 & 2,7 & 40 & 48 & 4,8 & 80 \\
\hline & Indet. $14 *$ & 25 & 2,5 & 80 & 104 & 10,4 & 40 \\
\hline \multirow[t]{2}{*}{ SOLANACEAE } & Solanum sp. 01 & 23 & 2,3 & 20 & 0 & 0 & 0 \\
\hline & Solanum sp. 02 & 19 & 1,9 & 60 & 12 & 1,2 & 50 \\
\hline EUPHORBIACEAE & Mabea fistulifera Mart. & 17 & 1,7 & 20 & 0 & 0 & 0 \\
\hline CANNABACEAE & Trema micrantha Blume & 13 & 1,3 & 30 & 0 & 0 & 0 \\
\hline ASTERACEAE & Vernonanthura diffusa (Less.) H.Rob. & 10 & 1 & 50 & 1 & 0,1 & 10 \\
\hline FABACEAE & Anadenanthera peregrina (L.) Speng. & 10 & 1 & 20 & 18 & 1,8 & 30 \\
\hline INDETERMINADA & Indet. 5 & 10 & 1 & 10 & 0 & 0 & 0 \\
\hline ANNONACEAE & Rollinia sp. & 9 & 0,9 & 30 & 1 & 0,1 & 10 \\
\hline MORACEAE & Maclura tinctoria (L.) D.Don ex Steud. & 7 & 0,7 & 30 & 0 & 0 & 0 \\
\hline RUBIACEAE & Coffea arabica $\mathrm{L}$. & 7 & 0,7 & 20 & 1 & 0,1 & 10 \\
\hline ANACARDIACEAE & Tapirira guianensis Aubl. & 6 & 0,6 & 10 & 0 & 0 & 0 \\
\hline INDETERMINADA & Indet. 18 & 6 & 0,6 & 20 & 0 & 0 & 0 \\
\hline FABACEAE & Rhynchosia minima (L.) DC. & 5 & 0,5 & 20 & 0 & 0 & 0 \\
\hline BIGNONIACEAE & Indet. 2 & 4 & 0,4 & 30 & 3 & 0,3 & 10 \\
\hline MELIACEAE & Trichilia pálida Mart. & 4 & 0,4 & 10 & 0 & 0 & 0 \\
\hline SALICACEAE & Casearia. Arborea (Rich.) Urb. & 4 & 0,4 & 20 & 0 & 0 & 10 \\
\hline \multirow[t]{2}{*}{ INDETERMINADA } & Indet. 23 & 4 & 0,4 & 30 & 1 & 0,1 & 10 \\
\hline & Indet. 28 & 4 & 0,4 & 10 & 1 & 0,1 & 10 \\
\hline APOCYNACEAE & Aspidosperma sp. & 3 & 0,3 & 20 & 0 & 0 & 0 \\
\hline ERYTHROXYLACEAE & Erythroxylum pelleterianum A. St. Hil. & 3 & 0,3 & 20 & 16 & 1,6 & 30 \\
\hline \multirow[t]{2}{*}{ INDETERMINADA } & Indet. 8 & 3 & 0,3 & 10 & 0 & 0 & 0 \\
\hline & Indet. 35 & 3 & 0,3 & 10 & 1 & 0,1 & 10 \\
\hline ANNONACEAE & Rollinia silvatica Mart. & 2 & 0,2 & 10 & 1 & 0,1 & 10 \\
\hline LAURACEAE & Persea sp. & 2 & 0,2 & 10 & 0 & 0 & 0 \\
\hline
\end{tabular}

Revista Árvore, Viçosa-MG, v.39, n.3, p.475-485, 2015 
Tabela 2 - Cont.

Table 2 - Cont.

\begin{tabular}{|c|c|c|c|c|c|c|c|}
\hline \multirow{2}{*}{ Família } & \multirow{2}{*}{ Espécie } & \multicolumn{3}{|c|}{ Floresta inicial } & \multicolumn{3}{|c|}{ Floresta avançada } \\
\hline & & $\mathrm{N}$ & $\mathrm{DA}\left(\mathrm{m}^{2}\right)$ & FA (\%) & $\mathrm{N}$ & $\mathrm{DA}\left(\mathrm{m}^{2}\right)$ & FA $(\%)$ \\
\hline \multirow[t]{5}{*}{ INDETERMINADA } & Indet. 2 & 2 & 0,2 & 20 & 5 & 0,5 & 20 \\
\hline & Indet. 10 & 2 & 0,2 & 10 & 0 & 0 & 0 \\
\hline & Indet. 11 & 2 & 0,2 & 20 & 0 & 0 & 0 \\
\hline & Indet. 27 & 2 & 0,2 & 20 & 0 & 0 & 0 \\
\hline & Indet. 32 & 2 & 0,2 & 10 & 6 & 0,6 & 20 \\
\hline APOCYNACEAE & Indet. 1 & 1 & 0,1 & 10 & 0 & 0 & 0 \\
\hline ARECACEAE & Syagrus romanzoffiana (Cham.) Glassm. & 1 & 0,1 & 10 & 1 & 0,1 & 10 \\
\hline \multirow[t]{2}{*}{ BIGNONIACEAE } & Jacaranda sp. & 1 & 0,1 & 10 & 0 & 0 & 0 \\
\hline & Indet. 1 & 1 & 0,1 & 10 & 6 & 0,6 & 40 \\
\hline \multirow[t]{2}{*}{ LAURACEAE } & Ocotea laxa Mez & 1 & 0,1 & 10 & 0 & 0 & 0 \\
\hline & Indet. 01 & 1 & 0,1 & 10 & 0 & 0 & 0 \\
\hline MALVACEAE & Ceiba speciosa (A. St.-Hi1.) Ravenna. & 1 & 0,1 & 10 & 0 & 0 & 0 \\
\hline SAPINDACEAE & Indet. 01 & 1 & 0,1 & 10 & 0 & 0 & 0 \\
\hline SOLANACEAE & Indet. 01 & 1 & 0,1 & 10 & 0 & 0 & 0 \\
\hline \multirow[t]{11}{*}{ INDETERMINADA } & Indet. 6 & 1 & 0,1 & 10 & 0 & 0 & 0 \\
\hline & Indet. 9 & 1 & 0,1 & 10 & 0 & 0 & 0 \\
\hline & Indet. 12 & 1 & 0,1 & 10 & 0 & 0 & 0 \\
\hline & Indet. 15 & 1 & 0,1 & 10 & 8 & 0,8 & 30 \\
\hline & Indet. 20 & 1 & 0,1 & 10 & 0 & 0 & 0 \\
\hline & Indet. 22 & 1 & 0,1 & 10 & 0 & 0 & 0 \\
\hline & Indet. 25 & 1 & 0,1 & 10 & 0 & 0 & 0 \\
\hline & Indet. 26 & 1 & 0,1 & 10 & 1 & 0,1 & 10 \\
\hline & Indet. 30 & 1 & 0,1 & 10 & 0 & 0 & 0 \\
\hline & Indet. 31 & 1 & 0,1 & 10 & 0 & 0 & 0 \\
\hline & Indet. 36 & 1 & 0,1 & 10 & 0 & 0 & 0 \\
\hline FABACEAE & Dalbergia nigra Allem. Ex Benth. & 0 & 0 & 0 & 1 & 0,1 & 10 \\
\hline LECYTHIDACEAE & Cariniana estrellensis (Raddi) Kuntze. & 0 & 0 & 0 & 12 & 1,2 & 60 \\
\hline RUBIACEAE & Coutarea hexandra (Jacq.) K. Schum. * & 0 & 0 & 0 & 209 & 20,9 & 20 \\
\hline SALICACEAE & Casearia sp. 1 & 0 & 0 & 0 & 18 & 1,8 & 20 \\
\hline SAPINDACEAE & Allophylus edulis Radlk. Ex Warm. & 0 & 0 & 0 & 2 & 0,2 & 10 \\
\hline \multirow[t]{9}{*}{ INDETERMINADA } & Indet. $7 *$ & 0 & 0 & 0 & 63 & 6,3 & 50 \\
\hline & Indet. 16 & 0 & 0 & 0 & 1 & 0,1 & 10 \\
\hline & Indet. 17 & 0 & 0 & 0 & 3 & 0,3 & 20 \\
\hline & Indet. 19 & 0 & 0 & 0 & 1 & 0,1 & 10 \\
\hline & Indet. 21 & 0 & 0 & 0 & 1 & 0,1 & 10 \\
\hline & Indet. 24 & 0 & 0 & 0 & 1 & 0,1 & 10 \\
\hline & Indet. 29 & 0 & 0 & 0 & 1 & 0,1 & 10 \\
\hline & Indet. $34 *$ & 0 & 0 & 0 & 44 & 4,4 & 20 \\
\hline & Indet. 38 & 0 & 0 & 0 & 1 & 0,1 & 10 \\
\hline MYRTACEAE & Eucalyptus sp. & $* *$ & $* *$ & 20 & 0 & 0 & 0 \\
\hline
\end{tabular}

de sementes local. Entretanto, a chuva de sementes dos dois trechos pode ser considerada similar, conforme Mueller-Dombois e Ellenberg (1974), que consideram duas comunidades semelhantes quando o índice de Sorensen é igual ou superior a $50 \%$.

Pode-se salientar que a chuva de sementes, quando estudada por curto período, nem sempre reflete a vegetação local devido ao padrão supra-anual de floração e frutificação de determinadas espécies, detectado apenas com estudos de longo prazo (WALKER; NERIS, 1993). Entretanto, não revoga a realização de pesquisas conduzidas por período de no mínimo um ano, em razão da importância de inventariar as sementes precipitadas e, assim, diagnosticar o processo de dinâmica sucessional, que, a exemplo deste estudo, confirmou a contribuição das espécies pioneiras na

Revista Árvore, Viçosa-MG, v.39, n.3, p.475-485, 2015 
chuva de sementes em ambos os estádios sucessionais, seja para atuar no banco de sementes, no avanço do fragmento ou, mesmo, na colonização de novas áreas, exercendo papel fundamental no processo sucessional do ecossistema.

Importante ressaltar que sementes de espécies ausentes na florística da comunidade podem estar compondo a chuva de sementes local. Portanto, a chuva de sementes não necessariamente deverá refletir fielmente a comunidade estudada. Destacando ainda que o padrão supra-anual de floração e frutificação é fenômeno verificado em determinadas espécies presentes na comunidade, como é o caso da Dalbergia nigra, inventariada neste trabalho, cujo comportamento sazonal e contribuição para dinâmica sucessional pode ser mais bem elucidado em estudos prolongados e, ou, pesquisas de outra natureza.

\section{CONCLUSÃO}

No período de um ano, a quantidade de sementes depositadas no solo da floresta inicial foi 10 vezes superior à quantidade depositada na floresta avançada. $\mathrm{Na}$ análise de ambos os trechos sucessionais, prevaleceu maior número de sementes de hábito arbóreo, na sua maioria depositadas pela dispersão zoocórica. As sementes das espécies Cecropia hololeuca e $C$. glaziovii, ambas de dispersão zoocórica, foram as mais abundantes na chuva de sementes, estando presentes toda a área amostral. A similaridade florística entre as sementes e as espécies amostradas na floresta inicial demonstra que a chuva de sementes da comunidade local é a principal fonte formadora do banco de sementes nesse trecho, o que não ficou evidente no trecho de floresta avançada.

\section{AGRADECIMENTOS}

Ao Conselho Nacional de Desenvolvimento Científico e Tecnológico (CNPq), pelo auxílio a esta pesquisa e pela bolsa concedida.

\section{REFERÊNCIAS}

ANGIOSPERM PHYLOGENY GROUP II - APG II. An update of the Angiosperm Phylogeny Group classification for the orders and families of flowering plant: APG II. Botanical Journal of the Linnaean Society, v.141, n.4, p.399-436, 2003.
ARAÚJO, M.M.; LONGHI, S.J.; BARROS, P.L.C.; BRENA, D.A. Caracterização da chuva de sementes, banco de sementes do solo e banco de plântulas em floreta estacional decidual ripária Cachoeira do Sul, RS, Brasil. Scientia

Forestalis, v.66, n.1, p.128-141, 2004.

AUGSPURGER, C.K.; KELLY, C.K. Pathogen mortality of tropical tree seedlings: experimental studies of the effects of dispersal distance, seedling density, and light conditions.

Oecologia, v.61, n.1, p.211-217, 1984.

BRAGA, A.J.T.; MARTINS, S. V.; BORGES, E.E.L.; Florística e estrutura de dois trechos de uma floresta estacional Semidecidual, situada no campus da Universidade Federal de Viçosa, MG. Revista Árvore, v.35, n.3, p.493-503, 2011.

CAMPOS, E.P.; VIEIRA, M.F.; SILVA, A.F.; MARTINS, S.V.; CARMO, F.M.S.; MOURA, V.M.; RIBEIRO, A.S.S. Chuva de sementes em floresta estacional semidecidual em Viçosa, MG, Brasil. Acta Botanica Brasilica, v.23, n.2, p.451-458, 2009.

CASTRO, P.S.;VALENTE, D.F.; COELHO, D.F.; RAMALHO, R.S. Interceptação da chuva por mata natural secundária na região de Viçosa, MG. Revista Árvore, v.7, n.1, p.76-9, 1983.

FERREIRA JÚNIOR, W.G.; SCHAEFFER, C.E.G.R.; SILVA, A.F. Uma visão pedogeomorfológica sobre as formações florestais da Mata Atlântica. In: MARTINS, S.V. (Ed.). Ecologia de florestas tropicais do Brasil. Viçosa: Editora UFV, p.109-142, 2012.

GANDOLFI, S.; LEITÃO FILHO, H.F.; BEZERRA, C.L.F. Levantamento florístico e caráter sucessional das espécies arbustivo-arbóreas de uma floresta mesófila semidecídua no município de Guarulhos, SP. Revista Brasileira de Biologia, v.55, n.4, p.753-767, 1995.

GENTRY, A.H. Dispersal ecology and diversity in neotropical forest communities. Sonderbände Naturwissenschaftlichen Vereins im Hamburg, v.7, n. 1, p.315-352, 1983.

GROMBONE-GUARATINI, M.T.; RODRIGUES, R.R. Seed bank and seed rain in a seasonal semideciduous forest in south-eastern Brazil. 
Journal of Tropical Ecology, v.18, n.1, p.759-774, 2002.

HARPER, J.L. Population biology of plants. London: Academic Press, 1977. 892p.

HOFGAARD, A. Seed rain quantity and quality, 1984-1992, in a high altitude old-growth spruce forest, northern Sweden. New Phytologist, v.125, n.1, p.635-640, 1993.

LEITÃO-FILHO, H.F.; PAGANO, S.N.; CÉSAR, O.; TIMONI, J.L.; RUEDA, J.J. Ecologia da Mata Atlântica em Cubatão. Campinas: UNESP/ UNICAMP, 1993. 184p.

MARTINI, A.M.Z. ; SANTOS, F.A.M. Effects of distinct types of disturbance on seed rain in the Atlantic forest of NE Brazil. Plant Ecology, v.190, n.20, p.81-95, 2007.

MARTINS, S.V.; PELLEGRINI, M.C.; MARANGON, L.C. Composição florística e estrutura de uma floresta secundária no município de Cruzeiro-SP. Revista Árvore, v.26, n.1, p.35-41, 2002.

MARTINS, S.V.; RODRIGUES, R.R. Gap-phase regeneration in a semideciduous mesophytic forest, south-eastern Brazil. Plant Ecology, v.163, n.1, p.51-62, 2002.

MUELLER-DOMBOIS, D.; ELLENBERG, H. Aims and methods of vegetation ecology. New York: John Wiley \& Sons, 1974. 547p.

PENHALBER, E.F.; MANTOVANI, W. Floração e chuva de sementes em mata secundária em São Paulo, SP. Revista Brasileira de Botânica, v.20, n.1, p.205-220, 1997.

van der PIJL. Principles of dispersal in higher plants. $2^{\mathrm{a}}$ ed. Berlim: Springer-Verlag, 1982. 450p.

VELOSO, H.P.; RANGEL-FILHO, A.L.R.; LIMA, J.C.A. Classificação da vegetação brasileira adaptada a um sistema universal. Rio de Janeiro: IBGE, 1991. 123p.

WALKER, L.A.; NERIS, L.E. Posthurricane seed rain dynamics in Puerto Rico. Biotropica, v.25, n.1, p.408-418, 1993.

YAMAMOTO, L.F.; KINOSHITA, L.S.; MARTINS, F.R. Síndromes de polinização e de dispersão em fragmentos da Floresta Estacional Semidecídua Montana, SP, Brasil. Acta Botanica Brasílica, v.21, n.3, p.553-573, 2007. 